\title{
The Retinal Wholemount Technique: A Window to Understanding the Brain and Behaviour
}

\author{
Jeremy F.P. Ullmann ${ }^{a}$ Bret A. Moore ${ }^{c}$ Shelby E. Temple ${ }^{a}$ \\ Esteban Fernández-Juricic ${ }^{c}$ Shaun P. Collin ${ }^{a, b}$ \\ aSchool of Biomedical Sciences, The University of Queensland, Brisbane, Qld., and ${ }^{\mathrm{b}}$ School of Animal Biology and \\ the UWA Oceans Institute, The University of Western Australia, Perth, W.A., Australia; ' Department of Biological \\ Sciences, Purdue University, West Lafayette, Ind., USA
}

\section{Key Words}

Vision · Ganglion cell $\cdot$ Photoreceptor $\cdot$ Oil droplet $\cdot$ Visual acuity $\cdot$ Neuroethology $\cdot$ Topography $\cdot$ Behavioural ecology

\begin{abstract}
The accessibility of the vertebrate retina has provided the opportunity to assess various parameters of the visual abilities of a range of species. This thin but complex extension of the brain achieves a large proportion of the necessary visual processing of an optical image before information is delivered to the brain as neural impulses. Studies of the retina as a wholemount or a flattened sheet of neural tissue are abundant due to the large amount of information that can be analysed, as follows: the level of summation or convergence; the coverage, stratification and potential sites of synaptic connections; the spatial resolving power; the arrangement of neuronal arrays or mosaics; electrophysiological access for the recording of responses to visual stimuli; the spatial arrangement of cell dendritic fields; location of retinal 'blind spots' (optic nerve, falciform process and pecten); topographic differences in retinal cell sampling; spectral filters, and reflective structures. The present study examines all aspects of the wholemount technique, including enucleation, fixation, retinal extraction, flattening, staining, visualization of labelled cells and stereological mapping of cell density. Uniquely, it highlights the crucial technical and often spe-
\end{abstract}

cies-specific differences encountered when examining a range of vertebrate taxa (fishes, reptiles, birds and mammals). This broad comparative approach will enable future studies to overcome technical difficulties, thus permitting larger conceptual questions to be posed regarding the diversity of visual tasks across phylogenetic boundaries.

Copyright $\odot 2011$ S. Karger AG, Basel

\section{Introduction}

The retina is one of the most easily accessible parts of the central nervous system in vertebrates. This thin sheet of nervous tissue that lines the back of the eye processes the optical image of the visual field, transforming light energy into electrical signals (i.e. phototransduction) to form a neural image interpretable by the rest of the brain. Physically isolated from the rest of the central nervous system, it provides a window through which to examine how each species perceives their environment, a conduit for visual information that is filtered and processed by the brain before being used in the initiation of behaviours.

This year marks 30 years since the publication of The Wholemount Handbook. A Guide to the Preparation and Analysis of Retinal Wholemounts by Stone [1981]. In his handbook, Stone [1981] presented the wholemount technique and numerous methods for visualizing ganglion

\section{KARGER}

Fax +4161306 1234

E-Mail karger@karger.ch

www.karger.com

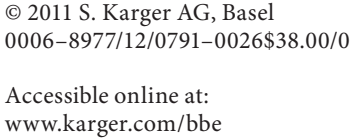

Jeremy F.P. Ullmann

School of Biomedical Sciences

The University of Queensland

Brisbane, QLD 4072 (Australia)

Tel. +61 73409 9058, E-Mail j.ullmann@uq.edu.au 
cells predominantly but also photoreceptor cells in the cat and turtle. Various additional staining techniques using cresyl violet, methylene blue, catecholamine fluorescence, Golgi and reduced silver impregnation methods were also included in the text, as well as the cellular preservation and visualization of a stable reaction product following incorporation of various retrograde tracers such as horseradish peroxidase into the optic nerve. Stone's [1981] technical monograph laid the foundation for what was to become a vital tool in the neurosciences, one which has taken full advantage of the plethora of fluorescent labels now available to intracellularly stain neurons.

The retinal wholemount technique is a useful method of assessing the structure, arrangement and sampling of retinal neurons in vertebrate eyes. Numerous visual parameters can be determined with the wholemount technique, including:

1 The degree of summation or convergence of information between photoreceptor and ganglion cell populations, by examining cell distributions on the same retina and at each of the retinal loci and then constructing topographic maps to identify the levels of summation across the retina [Litherland and Collin, 2008].

2 Coverage, stratification and potential sites of synaptic connections with other retinal neurons following the injection of intracellular dyes [Dacey and Peterson, 1992; Vaney et al., 1989] and either in vitro (living and superfused with physiological Ringer's solution) or retrograde labelling from the optic nerve in vivo [Collin, 1989b].

3 Spatial resolving power of the optical (using the photoreceptor spacing) and neural (using the ganglion cell spacing) image when combined with measures of focal length and/or posterior nodal distance (PND) [Collin and Pettigrew, 1989; Pettigrew et al., 1988]. Estimating spatial resolving power across species has been essential to study the evolution of visual acuity in species with different life histories and different activity periods [Garamszegi et al., 2002].

4 Spatial arrangement of neuronal arrays (regular and irregular mosaics) with increasing eccentricity most easily visualized for photoreceptors using Nomarski or differential interference contrast optics [Collin et al., 2004; Litherland and Collin, 2008] in order to assess chromatic sampling and motion sensitivity.

5 Intracellular electrophysiological recording of responses to visual stimuli in superfused wholemounted retinas incubated in Ringer's solution and maintained at optimal recording temperature [Wong et al., 2005]. Multiple simultaneous recording electrodes are currently being used to record 'waves' of activity across the retina [Segev et al., 2007; Wong et al., 1993].

6 Confocal measurements of neurons and their dendritic fields using both two-dimensional and three-dimensional (z-series) analysis [Koch et al., 2010], enabling more accurate assessment of retinal coverage and the relationship/connectivity with other neuron types.

7 Topographic arrangement and density of natural features of neurons, such as intracellular oil droplets and yellow filters [Hart et al., 1999], fluorescent tagged probes in retinal tissue incubated for in situ hybridization and identification of visual pigment opsins [Bowmaker et al., 1997; Schiviz et al., 2008; Takechi and Kawamura, 2005] and other neurons or glia pre-labelled using immunohistochemistry, Golgi and silver staining techniques and/or cells retrogradely labelled using carbocyanine dyes [Thanos et al., 1992; VidalSanz et al., 1988]. These parameters are used in the study of the evolution of colour vision and spectral tuning in vertebrates [Collin et al., 2009; Collin and Trezise, 2004; Collin and Trezise, 2006].

8 The location, size and shape of fundal landmarks such as the avian pecten [Brach, 1977; Smith et al., 1996], the teleost falciform process [Collin and Pettigrew, 1988a], the reptilian conus [Dieterich et al., 1976], the hyaline vasculature [Collin, 1989a; Collin and Pettigrew, 1988a; Dunlop et al., 1997] and the location of the optic nerve head [Frank and Goldberg, 1983]. These features define the position of blind spots and the influences of a vascular blood supply on acute vision.

9 Topographic differences in the concentration of reflective structures (tapetal material) underlying the retina, which can be used as an indicator of retinal regions of enhanced sensitivity in species occupying low light environments [Ollivier et al., 2004; Somiya, 1980; Takei and Somiya, 2002].

10 Peak spectral sensitivities of multiple photoreceptors arranged into two-dimensional arrays simultaneously [Levine et al., 1979]. This could enable efficient sampling across large retinal regions, in order to ascertain the presence of intra-retinal variability [Levine et al., 1979; Temple, 2011; Temple et al., 2010].

Examination of the retina using the retinal wholemount technique has enabled us to investigate the visual capabilities of over 300 species of vertebrates. Many papers have been written, with over 150 published in Brain, Behavior and Evolution just in the past decade. The large 
amount of information produced using the technique and its utility in facilitating comparative studies has been highlighted by the creation of two resources. The first is a public archive of retinal topography maps (see http:// www.retinalmaps.com.au/) which, together with relevant information about eye size, retinal cell density, retinal orientation, cell number, spatial resolving power and the type of retinal specialization, provides a searchable online resource of over 1,200 topography maps for 300 species across all vertebrate taxa, and the second is an international working group on the 'Evolutionary shifts in vertebrate visual ecology and visual morphology' supported by the National Evolutionary Synthesis Centre in the USA. A large number of the studies this working group is conducting are based on papers that used the retinal wholemount technique.

The present study includes (1) a detailed protocol for the retinal wholemount technique, including numerous technical refinements that we have developed for specific taxa, (2) issues relevant to the use of theoretical calculations based on data extracted using this technique, e.g. the differentiation of cell types and the calculation of spatial resolving power, and (3) the breadth and utility of the retinal wholemount technique and its major applications, not only to neuroscience but also other disciplines (e.g. visual ecology, visual physiology, behavioural ecology). We provide information that will hopefully improve methodological standardization of the wholemount technique when used across a diversity of phyla. This should in turn facilitate comparative research and meta-analyses, which will enhance our understanding of the plasticity, adaptation and evolution of the visual system of vertebrates.

\section{Materials and Methods}

The comprehensive protocol detailed in this paper is the product of over 20 years of research. During this time, we have examined a multitude of species from the two largest vertebrate groups, the birds and fishes. To supplement our technical knowledge in these classes of vertebrates, we have also performed an extensive literature review. The result is a complete methodology that ranges from enucleation of the eye to the creation of topographic maps. For many of the steps, we provide different options depending on the organisms being examined. For example, to open the eyeball in birds we recommend hemisecting the retina, while for teleosts we suggest removing the cornea (the transparent window that covers the iris, pupil and anterior chamber). In addition, we describe procedures for the following: the removal of the vitreous humour (gel-like liquid that fills the cavity of the eye) by enzymatic digestion, which is vital for analysis of deep-sea teleosts; bleaching of the pigmented cell layer found between the retina and the choroid called the retinal pigmented epithelium (RPE), which is helpful in
Table 1. Basic cresyl violet staining protocol

\begin{tabular}{|c|c|c|c|}
\hline Stage & Staining tray & Time & Purpose \\
\hline 1 & Histoclear & $10 \mathrm{~min}$ & clearing agent \\
\hline 2 & Histoclear & $10 \mathrm{~min}$ & clearing agent \\
\hline 3 & $100 \%$ ethanol & $2 \min$ & defatting $^{1}$ \\
\hline 4 & $100 \%$ ethanol & $2 \min$ & defatting $^{1}$ \\
\hline 5 & $90 \%$ ethanol & $2 \mathrm{~min}$ & rehydration \\
\hline 6 & $70 \%$ ethanol & $2 \min$ & rehydration \\
\hline 7 & $20 \%$ ethanol & $2 \mathrm{~min}$ & rehydration \\
\hline 8 & distilled water & $2 \mathrm{~min}$ & rehydration \\
\hline 9 & $0.1 \%$ cresyl violet $^{2}$ & $20 \min ^{3}$ & staining \\
\hline 10 & distilled water ${ }^{4}$ & quick rinse & rehydration \\
\hline 11 & $20 \%$ ethanol & $30 \mathrm{~s}$ & dehydration \\
\hline 12 & $70 \%$ ethanol & $30 s$ & dehydration \\
\hline 13 & $90 \%$ ethanol & $30 \mathrm{~s}$ & dehydration \\
\hline 14 & differentiation solution & $1 \mathrm{~min}$ & differentiation \\
\hline 15 & $100 \%$ ethanol & $1 \mathrm{~min}$ & dehydration \\
\hline 16 & $100 \%$ ethanol & $1 \mathrm{~min}$ & dehydration \\
\hline 17 & $100 \%$ xylene or Histoclear & $2 \min ^{5}$ & clearing agent \\
\hline 18 & $100 \%$ xylene or Histoclear & $2 \min ^{5}$ & clearing agent \\
\hline
\end{tabular}

${ }^{1}$ This stage can be left for up to $24 \mathrm{~h}$.

${ }^{2}$ Higher concentrations can be used for a deeper, darker stain.

${ }^{3}$ Staining should be monitored using a compound microscope. Alter staining time appropriately, keeping in mind that some fading may occur later on during dehydration. Longer staining times will be required for visualization of ganglion cells lying within the inner nuclear layer.

${ }^{4}$ A preliminary analysis of the degree of staining and background clarity can be performed at this step by holding the retina to the light.

${ }^{5}$ This time can be extended if necessary. Xylene and Histoclear are miscible with Depex, used for cover-slipping.

taxa/species in which the RPE adheres closely to the photoreceptors (e.g. birds and some teleosts); and visualizing photoreceptors and ganglion cells in the same retina, which permits the calculation of summation ratios within a single retina. For the first-time user of the wholemount technique, we have included a reagent and equipment list, a reagent setup, a basic cresyl violet staining protocol (table 1), a glossary and an extensive bibliography. Moreover, we have provided an example investigation of the archerfish Toxotes chatareus to demonstrate the utility of the protocol.

\section{Reagents}

The following reagents are required:

- $0.1 \mathrm{M}$ phosphate buffer (see Reagent Setup below)

- $4 \%$ paraformaldehyde (see Reagent Setup)

- formaldehyde

- nail varnish

- $100 \%$ glycerol

- Ames' medium (Sigma-Aldrich Pty. Ltd., Sydney, Australia)

- Gatenby's solution (see Reagent Setup)

- bleaching solution (see Reagent Setup)

- ethanol 
- xylene

- Histoclear

- $0.1 \%$ cresyl violet in acetate buffer (see Reagent Setup)

- differentiation solution (see Reagent Setup)

- Depex mounting media (Grale Scientific Pty. Ltd., Vic., Australia)

- Fluoromount aqueous mounting media (Sigma-Aldrich)

- sodium azide

- nitric acid

- hydrochloric acid

- hyaluronidase (Sigma-Aldrich).

Equipment

The necessary equipment is listed below:

- digital callipers

- 2 dissecting forceps No. 5 (Fine Science Tools Inc., Calif., USA)

- iridectomy scissors (Fine Science Tools)

- scalpel

- surgical blades No. 11

- razor blade

- 2 camel hair (natural animal hair) paintbrushes (can be purchased from art supply stores)

- slides (size depends on size of retina)

- cover slips (No. 1 thickness)

- Bunsen burner

- specimen block

- Kim wipes or tissue paper

- black Millipore filter paper (HABP02500, Millipore Pty. Ltd., Vic., Australia)

- glass staining dish

- 100-ml glass beaker

- heating tray

- graph paper

- dissecting microscope

- compound microscope with a stage with $\mathrm{x}$ - and $\mathrm{y}$-axis rulers

- eyepiece graticule with a $10 \times 10$ grid

- calibration slide

- digital camera

- compound microscope fitted with an X, Y and Z motorized stage

- Stereo Investigator software (MicroBrightField Inc., Vt., USA).

\section{Reagent Setup}

Standard $0.1 \mathrm{M}$ phosphate buffer at $\mathrm{pH} 7.4$ is suitable for this protocol. Store at $4^{\circ} \mathrm{C}$ and discard if precipitate forms.

Paraformaldehyde (4\%) is the fixative commonly used, prepared in $0.1 \mathrm{M}$ phosphate buffer.

An acid mixture is used to clean slides and the cover glass. Prepare by mixing 2 parts nitric acid to 1 part hydrochloric acid in a fume hood.

Gatenby's solution is used to sub the slides. Prepare by mixing Solution 1 into Solution 2, as follows:

- Solution 1: mix $2 \mathrm{ml}$ of distilled water and $0.1 \mathrm{~g}$ of chromium potassium sulphate (chrome alum).

- Solution 2: heat $1.5 \mathrm{~g}$ of gelatine in $7 \mathrm{ml}$ of glacial acetic acid until the gelatine dissolves.

Bleaching solution is prepared by mixing $90 \mathrm{ml}$ of $0.1 \mathrm{M}$ phosphate buffer ( $\mathrm{pH} 7.4$ ) and $10 \mathrm{ml}$ of $30 \%$ hydrogen peroxide. Adjust the $\mathrm{pH}$ to 11.95 using $1.0 \mathrm{M}$ potassium hydroxide (this will require approx. $80 \mathrm{ml}$ ).

The Retinal Wholemount Technique
Cresyl violet $(0.1 \%, \mathrm{pH} 3.7)$ in acetate buffer is prepared by mixing $0.4 \mathrm{~g}$ of cresyl violet, $10 \mathrm{ml}$ of glacial acetic acid, $10 \mathrm{ml}$ of $1.0 \mathrm{M}$ sodium acetate and $380 \mathrm{ml}$ of distilled water. Filter before use.

Differentiation solution is prepared by mixing $900 \mathrm{ml}$ of $95 \%$ ethanol and $1 \mathrm{ml}$ of glacial acetic acid.

\section{Results}

In the following we provide a detailed series of steps to successfully use the wholemount technique. Note that all the examples provided in this protocol were performed under the ethical guidelines of our respective research institutions.

Orientation and Enucleation of the Eye

Dark-adapt the animal for at least $2 \mathrm{~h}$ prior to dissection. In most teleost species, this facilitates the removal of the RPE. However, in other species, such as birds, we recommend timing the dissection to match the circadian rhythm of the animal with the time-period in which the RPE adheres less strongly working best (i.e. dissecting avian eyes in the evening tends to work better than in the morning). Prior to removing the eye, note any external characteristics that can be used later for orientating the eye (e.g. aphakic spaces, an area of the pupil through which light can reach the retina without first passing through the lens, or differences in pigmentation between the dorsal and ventral surfaces of the iris, a circular structure made up of two cellular layers, stroma and pigmented epithelial cells, which is responsible for controlling the diameter of the pupil; fig. 1). If none exist, it may be necessary to mark the eye by placing a small cut in the retina or alternatively mark the iris using a portable cautery. Gently rotate the eye forward and cut the conjunctiva (transparent mucous membrane that extends from the surrounding epidermis over the cornea or clear window of the eye). Gently pull the eye out of the orbit and cut away the adipose tissue, extraocular muscles and optic nerve. Be sure to leave a section of the optic nerve attached to the eye. Once the eye has been removed, cut away extraneous tissue, such as the extraocular muscles and connective tissue attached to the back of the eyecup. Measure the corneal diameter just outside the sclerotic ring/bones (rings of bony plates inside of the sclera which are present in many reptiles and birds) or where the cornea meets the sclera (the fibrous outer tissue covering the entire eye except for the cornea), as well as the transverse and axial lengths of the eye (fig. 2). Measurements should be taken at the point where the callipers make contact with the eye, but do not squeeze or depress the eye.

Brain Behav Evol 2012;79:26-44 

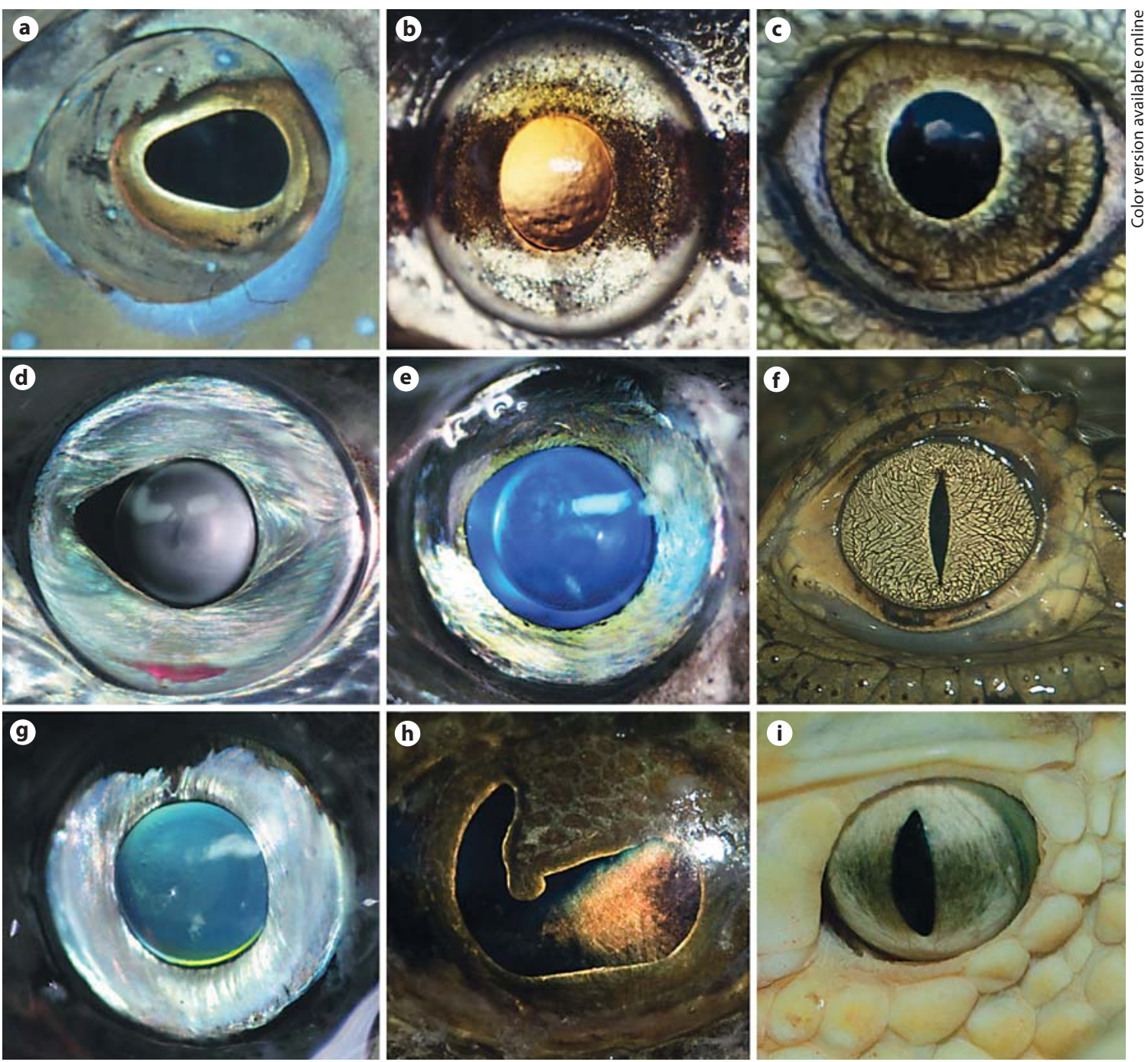

Fig. 1. Diversity of eye types showing a range of pupillary apertures, iris colourations, tapetal eye shines and aphakic gaps. a The coral trout, Plectropoma leopardus. b The Florida garfish, Lepisosteus platyrhincus. c The male Eastern water dragon, Physignathus lesueurii lesueurii. d Microstomatidae sp. e The myctophid
Triphoturus oculeus. $\mathbf{f}$ The spectacled caiman, Caiman crocodilus. g The slendertail lanternfish, Gonichthys tenuiculus. h The flathead Platycephalus fuscus. i The neotropical rattlesnake, Crotalus durissus.

11 blade) and scissors, first locate the ora serrata (the serrated junction found between the retina and the ciliary body that marks the progression from the non-photosensitive to the photosensitive area of the retina) and make sure to puncture the eye just above this area. Positioning the puncture below the ora serrata will damage the retina. Place the eye with the cornea face up and gently grasp it with a pair of forceps or with fingers if the eye is of sufficient size. For small eyes it can be suitable to 'corner' the eye in the ' $v$ ' between two fingers. Apply a slight pressure to the eye and then quickly puncture it. Be careful to keep 


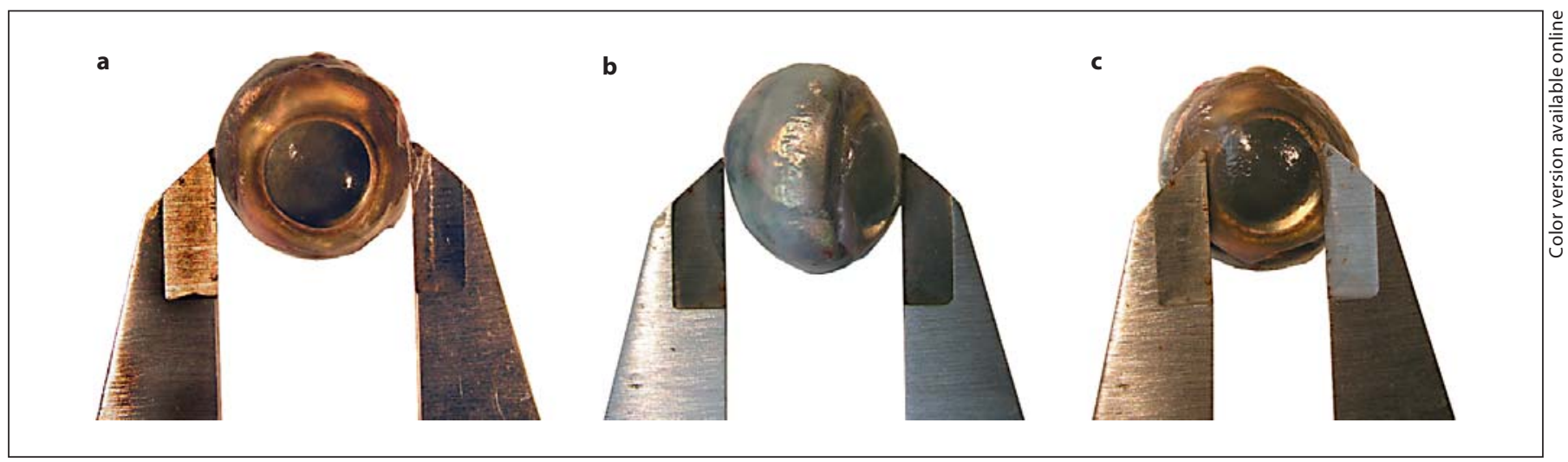

Fig. 2. Eye measurements. a Transverse length. b Axial length. c Corneal diameter.
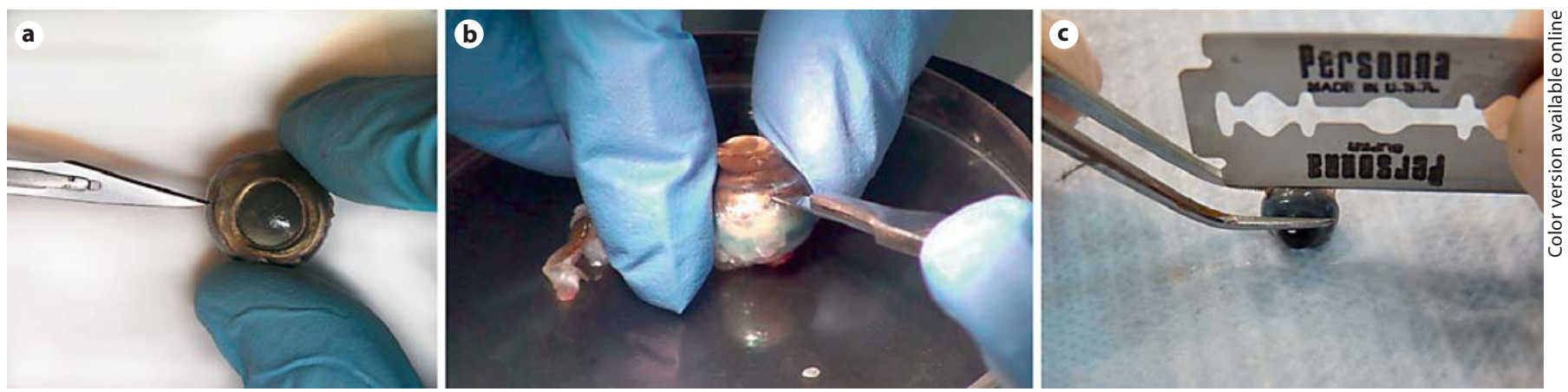

Fig. 3. Opening the eyeball. a Dorsal perspective of puncturing the eye using a scalpel. b Lateral perspective of scalpel technique. c Hemisecting the eye using a razor blade.

the scalpel blade parallel to the cornea to reduce the risk of damage to the retina (fig. 3a, b). If necessary, aim the scalpel blade slightly upwards. Create an incision at the border of the cornea and sclera (the limbus) large enough for a pair of iridectomy scissors to be inserted. Cut along the edge of the cornea and iris with the iridectomy scissors until the corneal surface of the eye has been removed. If using a razor blade to hemisect the eye, first stabilize the eye by gently squeezing the eye with forceps. Apply a slight downward pressure with one arm of the forceps to the top of the cornea, which will help stabilize the eye (fig. 3c). Make sure that the pupil is perpendicular to the table to ensure that the blade cuts straight. Locate the ora serrata and begin by slicing rather than pushing, using a delicate, long, slow sawing motion to make the initial cut. Follow by applying downward pressure while continuing to saw until the eye is completely hemisected. Cutting below (towards the back of the eye) the ora serrata will dam- age the retina and result in data loss, while placing the puncture too far above will make retinal extraction more difficult.

Once the cornea has been removed or the eye hemisected, examine the retina for physical landmarks that can be used to indicate orientation. Note whether it is the left or right eye and the orientation of dorsal, ventral, temporal and nasal poles. In mammals, the area centralis (a concentric increase in cell density towards the central area of acute vision) usually lies temporal to the optic disc (the area where ganglion cells exit the eye to make up the optic nerve; it contains no rods or cones and is therefore known as 'the blind spot') and therefore distinguishes the nasal and temporal sides of the retina; in birds, the pecten (a comb-like structure made up of blood vessels found in the vitreous body but part of the choroid) can be used to orientate the eye, and in some teleosts the position of the optic nerve head and/or the falciform process (a projection 

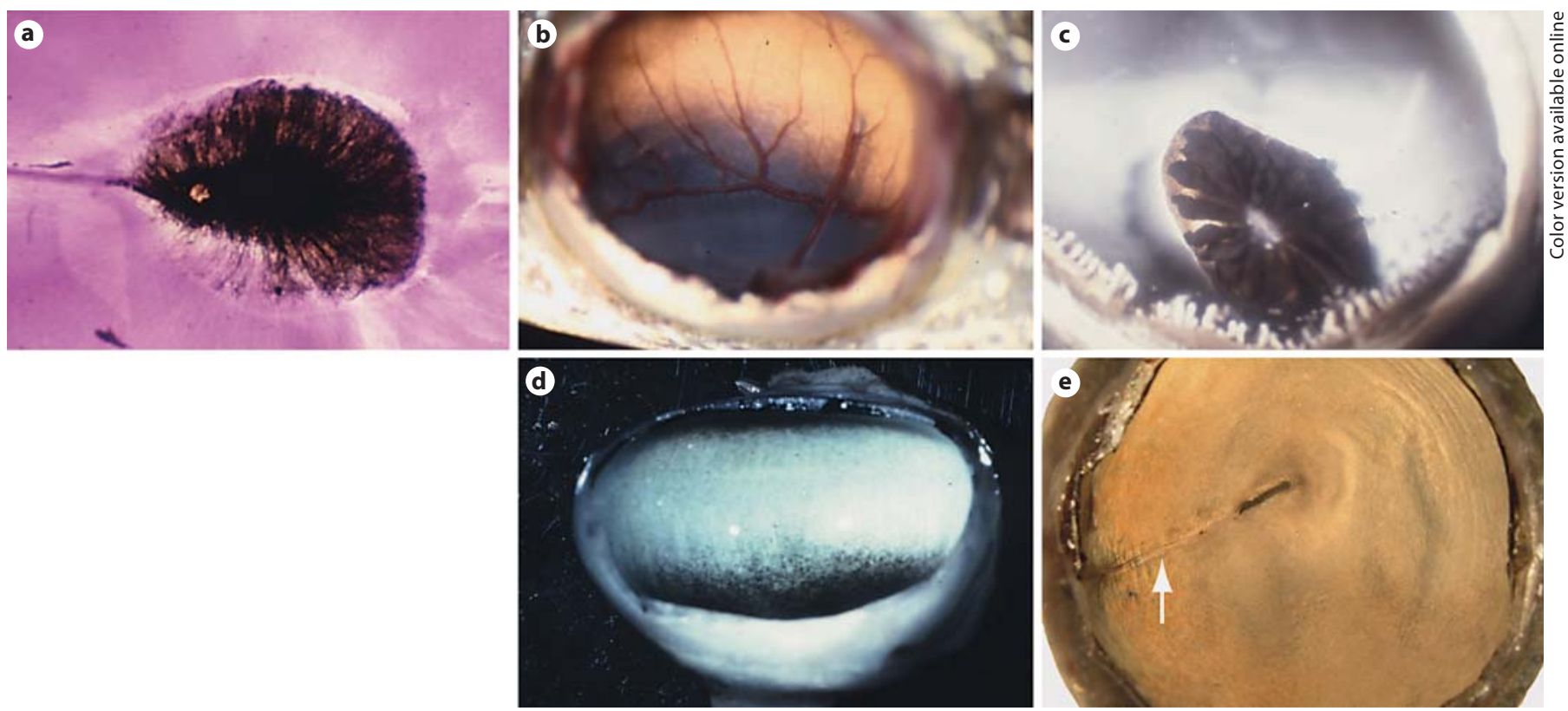

Fig. 4. View of the fundus in a variety of vertebrate eyes to depict the range of features present. a The pigmented optic nerve head of the reef fish Lethrinus chrysostomus tapering to a pigmented falciform process, which runs towards the ventral retinal margin. b Transition between the yellow tapetum (dorsal) and the ventral retina in the Florida garfish, Lepisosteus platyrhincus. Note the extensive vitreal vascularization of the inner retina em- anating from the elongated optic nerve. c The pleated folds of the large pecten of the ostrich, Struthio camelus. d Horizontal strip of choroidal tapetum of the giant shovel-nosed ray, Rhinobatos batillum. e Australian barramundi, Lates calcarifer. Note the well-defined falciform process (arrow) extending to the outer retina and the complete covering of the retina by the yellow tapetum. from the vascular structure in the floor of the eye) can be used (fig. 4). In order to ensure an accurate orientation of the eye, the position of physical landmarks within the fundus, or the interior surface of the eye opposite the lens, may need to be checked by hemisecting the eye while still in the orbit and attached to all the extraocular tissue of the euthanized animal. If no physical landmarks are present in the fundus, as in the monkey or human, place a deep incision in the retina and all layers of the eyecup in a predetermined location to act as an orientation marker. Be careful not to place the orientation slit where one might expect to find an important area, e.g. the area centralis. However, a few samples may have to be dissected before an appropriate place for the orientation slit can be decided upon. We recommend taking digital photographs throughout the dissection process until one is familiar with the physical characteristics of the eye of the species under study.

For lens extraction and measurements, use forceps to gently reach under the lens and pull it upwards. Alternatively, the lens may already have been extracted along with the anterior segment. Use iridectomy scissors to cut the lens free of the ciliary muscles (a ring of muscle found in the vascular layer that controls accommodation in mammals and birds) or the retractor/protractor lentis muscle and suspensory ligament (the ligament that connects the ciliary muscle to the lens) in aquatic, coldblooded vertebrates. Measure the equatorial and transverse diameters of the lens using digital callipers. Note that using a razor blade to hemisect the eye will cut the lens in half; so, if the lens is valuable to the study, it may be advisable to use a scalpel blade and iridectomy scissors.

\section{Retinal Extraction}

The retina can be fixed before or after removal from the eyecup, but for teleosts and reptiles, we recommend fixation prior to retinal removal, while for birds we recommend removing the fresh retina prior to fixation to prevent the RPE from binding to the retina too strongly. If an avian retina must be fixed prior to removal from the eyecup (e.g. in instances where there is not enough time as may be the case in the field), it is critical to remove most of the vitreous humour. Otherwise the retina will often wrinkle up. For fixing the retina before extraction, please 
skip forward to the retinal fixation section and then return to this section for the extraction procedure.

\section{Extraction of Retina for Superfusion, Intracellular}

Recording or Injection (before Fixation)

Dissect the retina from the rest of the eyecup while it is in carbogenated $\left(95 \% \mathrm{O}_{2} / 5 \% \mathrm{CO}_{2}\right)$ Ames' medium at the same temperature as the animal under investigation (e.g. $35-37^{\circ} \mathrm{C}$ for warm blooded animals). Mount the retina (scleral side up) on a glass slide, and place radial cuts (see the section Wholemounting the Retina below for more details) to allow it to lieflat. Cover the retina with black Millipore filter paper (HABP02500, Millipore). Place the filter paper and the adherent retina into the injection chamber with the retinal ganglion cell layer facing upwards. Superfuse the retina with carbogenated Ames' medium (e.g. $35-37^{\circ} \mathrm{C}$ ) at $1 \mathrm{ml} / \mathrm{min}$.

\section{Extraction of Retina for Wholemounting}

Place the eyecup in a specimen block (or Petri dish) filled with chilled $0.1 \mathrm{M}$ phosphate buffer ( $\mathrm{pH}$ 7.4) and visualize using a dissection microscope with a light source. Use forceps to grasp as much of the vitreous humour as possible and cut it away from the underlying retina, without causing the retina to be pulled up. Holding the vitreous humour from different locations in the eyecup and gently pulling upward out of the eyecup will allow areas in which the vitreous body membrane is attached to the retina to become visible. Cut as close as possible to the retina without damaging it. If possible, remove the entire body of the humour in one clump. In eyes that possess a pecten or falciform process, it is best to start on the side opposite these fundal landmarks where the vitreous will be easier to remove. If not all of the vitreous humour is removed, the eye will not lie flat on the slide and the penetration of the stain will be impeded. However, vitreous remnants can be removed during the flattening/ wholemounting step later. In some species, the vitreous is more difficult to remove and cannot be removed in toto (e.g. deep-sea fish). In such cases, additional vitreous can be removed enzymatically. Make up a viscous paste with a small amount of hyaluronidase (Sigma-Aldrich) and/or collagenase (Sigma-Aldrich) in phosphate buffer. Then add the paste directly to areas where the vitreous is still adhering. After a few minutes, rinse the eye with buffer to stop the reaction and remove the enzyme.

If the retina has already been fixed, begin the extraction procedure by first locating the edge of the retina, and, using a paintbrush or a pair of fine forceps, gently pull and cut the sclera away from the retina. Progressive- ly cut away small pieces of the sclera to expose the underlying choroid/choriocapillaris, a vascular layer of the eye found between the retina and the sclera, until only a small piece (attached to the optic nerve) remains. If the retina is torn during this step, the pieces of sclera being removed may be too large. Tears in the retina can be used later to assist in flattening the retina, but try to limit the number of tears by removing smaller pieces of sclera. The thickness of the retinal and non-retinal tissue often increases with the size of the animal. Therefore, a slight variation in the approach may need to be taken depending on the size of the animal. For smaller animals, such as small lizards, it is easier to carefully tear the sclera away in pieces rather than to try and insert scissors to cut the tissue.

If the retina has not yet been fixed, first locate the edge of the retina near the optic nerve/pecten, and, using a pair of fine forceps (e.g. Watchmakers No. 5), gently separate the choroid and RPE from the retina, gripping the sclera with another pair of forceps for stability. This relieves tension on the retina and enables a clearer visualization of the optic nerve from its origin at the back of the retina. Once the choroid and RPE have been removed from the retina around the optic nerve head/pecten, begin to pull the optic nerve inward through the sclera (cutting/tearing the nerve if necessary). Hypodermic needles can be used as microknives to cut the optic nerve if necessary, but pulling the optic nerve through the sclera is preferred. Gently pull the freed optic nerve with the attached retina out of the eyecup, pausing to tear/cut remaining points of strong attachment to the choroid. The thickness of the optic nerve is generally proportional to the size of the eye; thus, the procedure may need to be modified slightly. In larger species, pulling/tearing the optic nerve through the sclera may be difficult, upon which scissors or a microknife should be used. The retina may tend to curl up during the extraction procedure. Curling of the retina does not result in damage to the tissue because it does not cause tension at any point (unlike folds or bends). Fill the eyecup with chilled PBS to help the retina conform to a more natural position. If the retina is folding, creasing or bending, it may become discoloured at this point. If so, fill the eyecup with chilled PBS again. In larger species, the retina is also larger and is therefore difficult to manoeuvre, increasing the chance of folding. Leaving the vitreous inside the eyecup after detaching it from the retina may act as a cushion and help the retina to maintain its natural spatial orientation and shape. In species with smaller eyes, the retina is very thin and delicate. For these smaller species, careful manipulation of the retina is essential. 
Once the retina has been completely removed from the eyecup, grasp the optic nerve with one set of forceps and with another pair of forceps gently peel and, if necessary, cut away the choroid/choriocapillaris, the underlying RPE and, if present, any tapetal tissue (the layer of tissue found behind or within the retina that reflects visible light back through the retina). Begin peeling from the optic nerve and work towards the edge of the retina. If it is not possible to peel away the RPE, use an animal hair paintbrush to gently brush the RPE away from the back of the retina. Care should be taken when brushing away the RPE as it is possible to remove the photoreceptor inner/outer segments at the same time. Note that the RPE is denser than the retina, so with the retina submerged, pieces of RPE will sink to the bottom of the container. It is also brittle and can break into tiny granular pieces, so once removed from the retina, place discarded pieces of RPE away from the retina or wipe them from dissection tools with tissue paper. If layers of the retina are sloughing off while removing the RPE, the retina is under-fixed. If this occurs, it may be possible to place the retina back into the fixative. However, most likely a new eye will have to be dissected. Note that it may not be possible to completely remove the RPE, and therefore bleaching (see below) will then be required in order to produce a transparent retina suitable for staining and visualization with transmitted light. In larger species, the RPE is often quite thick and must be removed physically as the bleaching process will be less effective. Bleaching cannot be used if oil droplet distribution will be mapped, and thus the RPE must be removed physically with a brush. Bleaching will not be necessary if visualizing fluorescently labelled retinal neurons in wholemount. Finally, cut away the remaining optic nerve and sclera with a scalpel.

\section{Retinal Fixation}

Place the retina/eyecup in $4 \%$ paraformaldehyde in $0.1 \mathrm{M}$ phosphate buffer to fix the retina. Make sure there is enough fixative to completely submerge the entire retina/eyecup. This should equate to roughly 5 times the volume of the eye. The time of fixation varies depending on the size and thickness of the retina. A 1-cm-diameter teleost eye should be fixed for between 60 and $120 \mathrm{~min}$, while a bird eye of the same size may safely be fixed for between 12 and $24 \mathrm{~h}$ and the retina will still be successfully wholemounted. Remove the retina/eyecup from the fixative solution by grasping the retina/eyecup by the optic nerve. Then wash it in $0.1 \mathrm{M}$ phosphate buffer $(1 \mathrm{~min})$ to remove excess fixative (repeat 3 times). If the optic nerve has been cut off the retina, it is safer to remove the fixative from the container and then rinse the tissue in the original container by replacing the liquid and swirling the container with each rinse. Once the retina is fixed, samples can be stored in $0.1 \mathrm{M}$ phosphate buffer ( $\mathrm{pH}$ 7.4) at $4^{\circ} \mathrm{C}$ for several weeks; however, if leaving the retinae for a longer time period, $0.01-0.05 \%$ sodium azide should be added to inhibit bacterial growth [Lichstein and Soule, 1944].

\section{Bleaching the Retina}

Wash the retina in fresh $0.1 \mathrm{M}$ phosphate buffer and then replace the buffer with bleaching solution (see Reagent Setup). Completely submerge the retina; this should equate to at least 5 times the volume of the eye, depending on the volume of the container used. The length of time required to bleach the RPE is dependent on the thickness and amount of RPE remaining. During bleaching, the RPE will fade in colour from black to dark brown to light brown to yellow/clear (fig. 5). Additionally, bubbles will form along the edges of the retina. Be aware that during the bleaching process, the retina may change position and orientation. We suggest taking digital pictures throughout the process to assist with maintaining the orientation of the retina. In addition, leaving the retina in the bleaching solution too long will cause it to become progressively softer, eventually making it too delicate to handle. After the bleaching process is complete, replace the bleaching solution with $0.1 \mathrm{M}$ phosphate buffer and wash/rinse the retina twice for $1 \mathrm{~min}$ each time.

\section{Wholemounting the Retina}

A clean slide and cover slip are required for wholemounting the retina for photoreceptor visualization, while a clean and (previously) gelatinized slide is required if wholemounting is followed by staining for ganglion cell visualization. Clean the slides and cover glass by placing them into nitric and hydrochloric acid solutions (see Reagent Setup) for approximately $2 \mathrm{~h}$ with occasional swirling. Then rinse the slides and cover glass thoroughly with water and store in $70 \%$ ethanol. Finally, flame the slides and cover slips in a fume hood prior to use. Gelatinize glass slides (size dependent on the size of the retina) by cleaning the slides and dipping them into Gatenby's solution (see Reagent Setup) 3 times. Let the slides dry between dips. To decrease the drying time, place the slides into a warm oven $\left(37^{\circ} \mathrm{C}\right)$ or blow-dry them.

Float the retina onto either a gelatinized slide for ganglion cell visualization or a clean (but non-gelatinized) slide for photoreceptor visualization. Rotate the retina to match the orientation of the eye in the orbit/skull, noting 
Fig. 5. a-d Progressive bleaching of a retina. Note the appearance of air bubbles and the change in orientation of the retina.
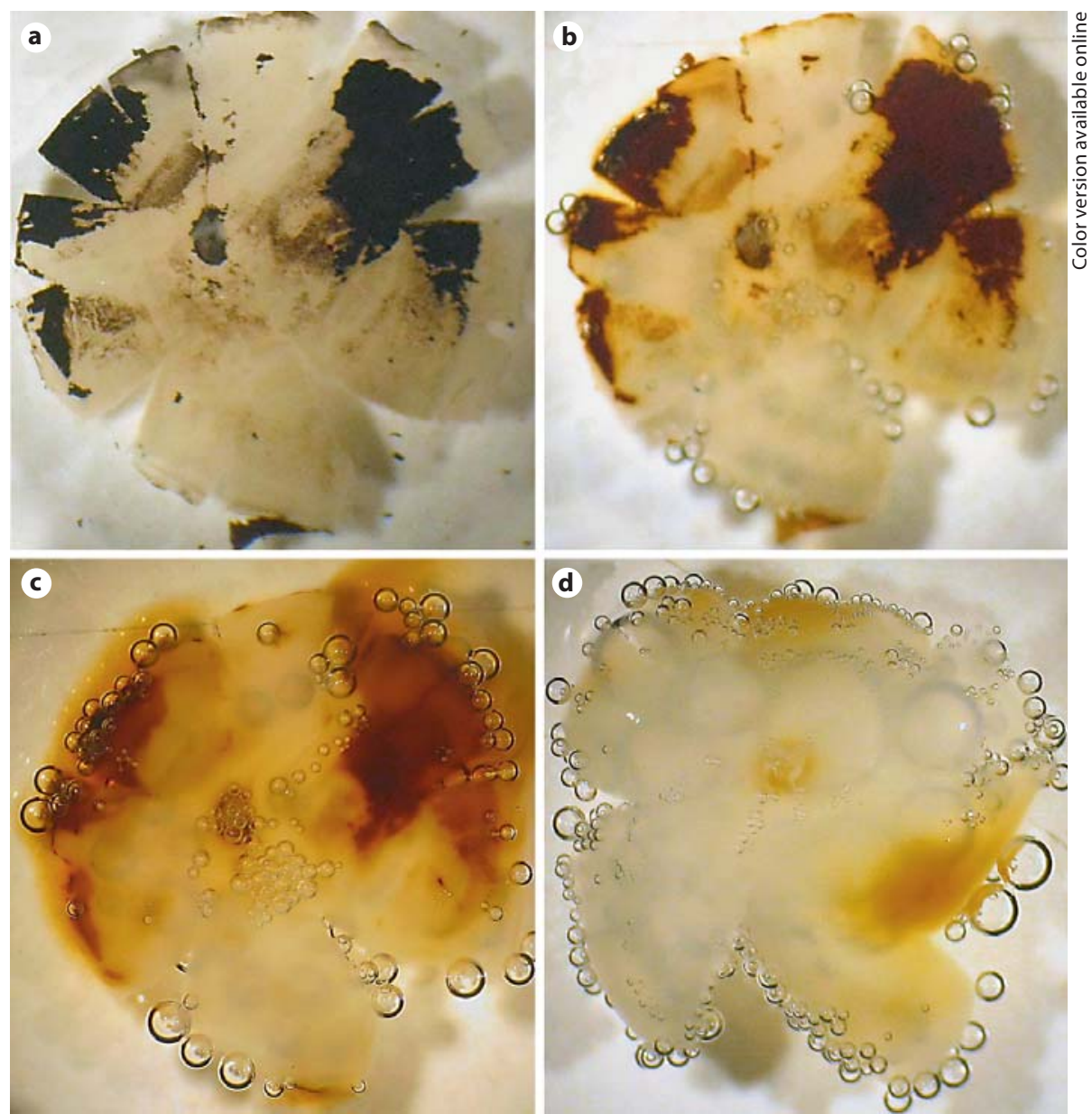

whether the eye is the left or right. To visualize photoreceptors, the inner (vitreal) surface of the retina should be mounted face down. Place the inner retina face up for ganglion cell visualization. Flatten the retina by making radial cuts with a scalpel blade or scissors around the periphery of the retina to release tension and allow it to lie flat. There are no set positions for where to best make radial cuts, as all retinas are different. However, if a rip or hole is already present in the retina (due to a difficulty during dissection), place a radial cut there or, if possible, place a radial cut along the falciform process or pecten (when present). Try not to place cuts in regions predicted to represent a retinal specialization (e.g. region of high cell density). If the retina possesses a pecten (birds) or conus, a cone-like structure located on the optic nerve head (reptiles), remove the pecten/conus and any other connective tissue with forceps and iridectomy scissors. Similarly, if parts of the optic nerve head are protruding (e.g. hyoid vasculature of teleosts), remove these carefully with scissors. This will allow the retina to lie completely flat and adhere to the slide. Use filter paper to soak up the excess buffer and a paintbrush to gently flatten the retina. By absorbing the excess liquid from underneath the retinal tissue, the retina will stick to the gelatine-coated slide. The retina may curl tightly in on itself. This often occurs when the retina has been fixed (especially for longer periods of time) after extraction and is normal. However, if it is difficult to uncurl and flatten, the retina may have been over-fixed (rubbery, hard or brittle), or some of the vitreous may still be attached. If the retina has been overfixed, placing it back in the bleaching solution will soften it. If there is any vitreous remaining, it must be removed prior to (flattening and) effective staining. Use scissors and forceps or filter paper to remove excess vitreous or, if difficult, use the hyaluronidase and/or collagenase slurry as described in the section Extraction of Retina for Wholemounting. Also, if the peripheral cuts do not penetrate enough towards the central retina, the retina will 
not lie flat. Use scissors to increase the size of the peripheral slits.

If the flattening procedure takes too long $(>10-20$ min) while mounting for ganglion cell visualization, the retina may not readily stick to the slide. This may be due to the gelatine on the gelatinized slide being washed away. In this case, transfer the retina to a new slide and continue the procedure. Double and triple subbing of the slide may also improve retinal adhesion, especially for large eyes.

Visualization, Staining and Labelling of Retinal Cells

Photoreceptors and ganglion cells can be viewed independently, on different retinas, or on the same retina if photoreceptors are examined before staining for ganglion cells.

\section{Photoreceptors}

To prevent the retina from being crushed and to allow the photoreceptors to maintain their natural orientation and density, create a spacer out of plastic, paper or tape and place this between the slide and cover slip. The spacer should be of a slightly greater thickness than the retina and have a hole in the middle large enough for the flattened retina to sit inside. Place the spacer onto the slide containing the retinal wholemount and glue the spacer to the slide using nail varnish (polish). The spacer is best fixed to the slide before the retina is transferred to the slide.

Place a few drops of $100 \%$ glycerol onto the buffersoaked retina such that the final proportion of liquid on the slide is $50 \%$ glycerol and $50 \%$ buffer. Place one edge of the cover slip on the slide and then gently lower the cover slip onto the retina using forceps. Lowering the cover slip down from one side will prevent bubbles from being trapped over the retina. Seal the cover slip to the plastic spacer with nail varnish, to reduce the risk of the retina being exposed to air. If the retina dries out, the photoreceptors will deteriorate and the slide will become useless.

Observe the photoreceptor array under a compound microscope. Nomarski or differential interference contrast optics will facilitate photoreceptor visualization and counting. If the photoreceptors appear squashed, the spacer is likely too thin and/or there may still be vitreous attached and/or the manual handling of the retina has been severe. To solve this problem, submerge the whole slide in PBS and remove the cover slip by breaking the seal around the edge with a scalpel blade using a twisting motion. Then gently slide the old cover slip off and re- place the plastic spacer with a thicker spacer. Take care to reduce direct contact with the photoreceptor layer.

Some taxa have oil droplets located within the inner segment of cone photoreceptors (e.g. some birds, reptiles, amphibians, fish and monotreme and marsupial mammals). Since each type of oil droplet is associated with a specific type of photoreceptor [Hart, 2002], the identification of different oil droplet types across the retina allows the distribution of different types of photoreceptors to be determined. In order to visualize the oil droplets, the retina has to be fresh (no fixation, no bleaching), mounted just as one would for ganglion cell visualization (see below). Mapping the oil droplet distribution is done in a similar manner as for ganglion cells (see below); however, to distinguish the different types of oil droplets, a combination of brightfield and fluorescent microscopy is necessary (for details, see Hart [2001]).

\section{Ganglion Cells}

To visualize and assess the ganglion cell population following assessment of the photoreceptors, slide a scalpel blade under the cover slip and slowly twist the handle to crack the cover slip. Use forceps to carefully remove the broken pieces of cover slip so as not to tear the underlying retina. Soak the entire slide in phosphate buffer to remove glycerol and assist in floating the retina off the slide. An animal hair paintbrush may be needed to gently detach the retina from the slide.

Float the retina (ganglion cell layer face up) onto a freshly gelatinized slide. Using a paintbrush, arrange the retina so that the inner retina is facing up and its orientation is consistent with the placement of the eyes/retina in the skull. Use a paintbrush to flatten the retina and to remove any air bubbles (fig. 6a). Use the paintbrush to ensure that the retina is well attached to the gelatinized slide at its edges. Photograph the entire retina beside a calibration tool (ruler or micrometer) in order to account for any shrinkage that will occur during the drying and staining processes. Dry the retina to the slide. Avoid over-drying as the retina will not stain well and it may even crack. This step can be performed using option 1 or 2 (below), depending on the urgency with which the sample is needed.

Option 1: place a damp (water) paper towel in an airtight box, followed by the slide, horizontally on a stand (e.g. the lid from a specimen tube). Then slowly decrease the moisture in the container by slightly opening its lid a little more each day. This will allow the retina to dry slowly over a period of several days.

Option 2: place the slide (horizontally) in a container with a lid together with a small piece of tissue paper 

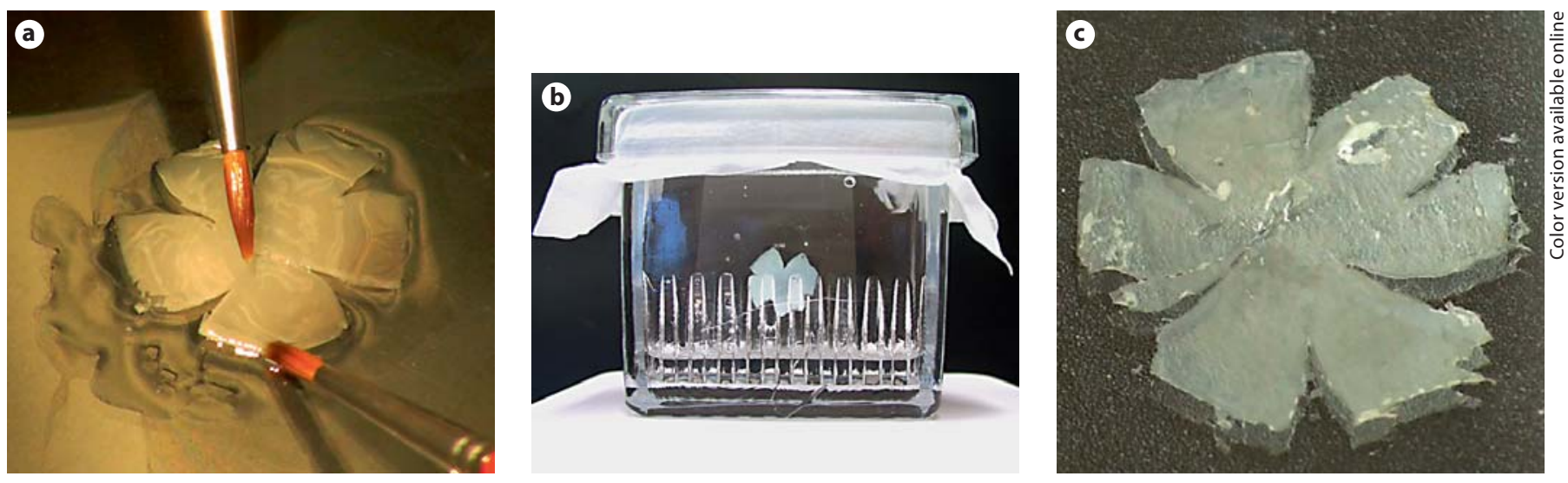

Fig. 6. Preparation of a retina for counting. a Flattening the retina using animal hair paintbrushes. b Rapid drying of a retina using a heating tray and formalin. c A dried retina ready for cresyl violet staining.

soaked in a few drops of $37 \%$ formalin (only vapours needed). Place a paper towel between the lid and the container to catch any condensation that forms on the lid, as droplets of water will ruin the retina (fig. $6 \mathrm{~b}$ ). Heat at $60^{\circ} \mathrm{C}$ for 30-120 min (depending on the size/thickness of the retina). Turn off the heat and let it sit overnight.

Stain the retina using a $0.1 \%$ cresyl violet solution. See Materials and Methods for a suggested protocol. Place a few drops of mounting media onto the retina and slowly lower a cover slip onto it from one side, to stop bubbles from being trapped over the retina. The cover slip should be large enough to cover the retina and extend a few millimetres beyond. Add mounting media around the edges of the cover slip, if necessary, in order to prevent any air bubbles from forming. Remove any excess mounting media with tissue paper. Take another photograph of the entire retina beside the same calibration tool and estimate the level of shrinkage.

Observe ganglion cells under a compound microscope. Ganglion cells usually possess an irregularly shaped soma with Nissl substance and a distinct nucleus, while amacrine and glial cells are either teardrop or slender in shape, respectively [Ehrlich, 1981]. If observing fluorescently labelled ganglion cells (either injected intracellularly or retrogradely labelled from the optic nerve), mount as per the photoreceptors. In this case, a mounting medium such as Fluoromount aqueous mounting medium (Sigma-Aldrich) can replace glycerol in order to inhibit fading. The wholemounted retina (stained with cresyl violet) protected with a cover slip will last for months to years, although the Nissl staining will fade over time. If this occurs, it is possible to remove the cover slip by soaking in xylene for days to weeks and repeating the staining and mounting.

\section{Mapping Cell Distributions}

This step can be performed using either an eyepiece graticule or stereological computer software, depending on the equipment available.

\section{Mapping with an Eyepiece Graticule}

Observe the retina under the compound microscope with a low-power objective to obtain the coordinates of the extremities of the retina (i.e. the coordinates of the outer and inner edges of the radial cuts). Draw a basic outline of the retina onto a piece of graph paper (fig. 7a). Use the coordinates to determine the scale for drawing the retina onto graph paper (suggested ratio 1:10 or 1:5). Carefully draw a preliminary outline of the retina onto graph paper. Scan the retina in approximately $1-\mathrm{mm}$ steps (smaller or larger steps can be used depending on the size of the retina) to confirm the coordinates of the retina outline and to add any relevant features (e.g. optic disc, falciform process, pecten, vitreal blood vessels and fovea) to the graph paper. This retinal outline and the lines of the graph paper will be used as a grid to record the location of each sample count.

Based on the area of the retina, determine the spacing needed between counting areas in order to obtain approximately 200 sampling areas per retina and an acceptable coefficient of error (CE; see below). The higher the number of sampling areas, the more accurate the subsequent topographic distribution map will be. Change to a higher-power objective and begin counting cells within 


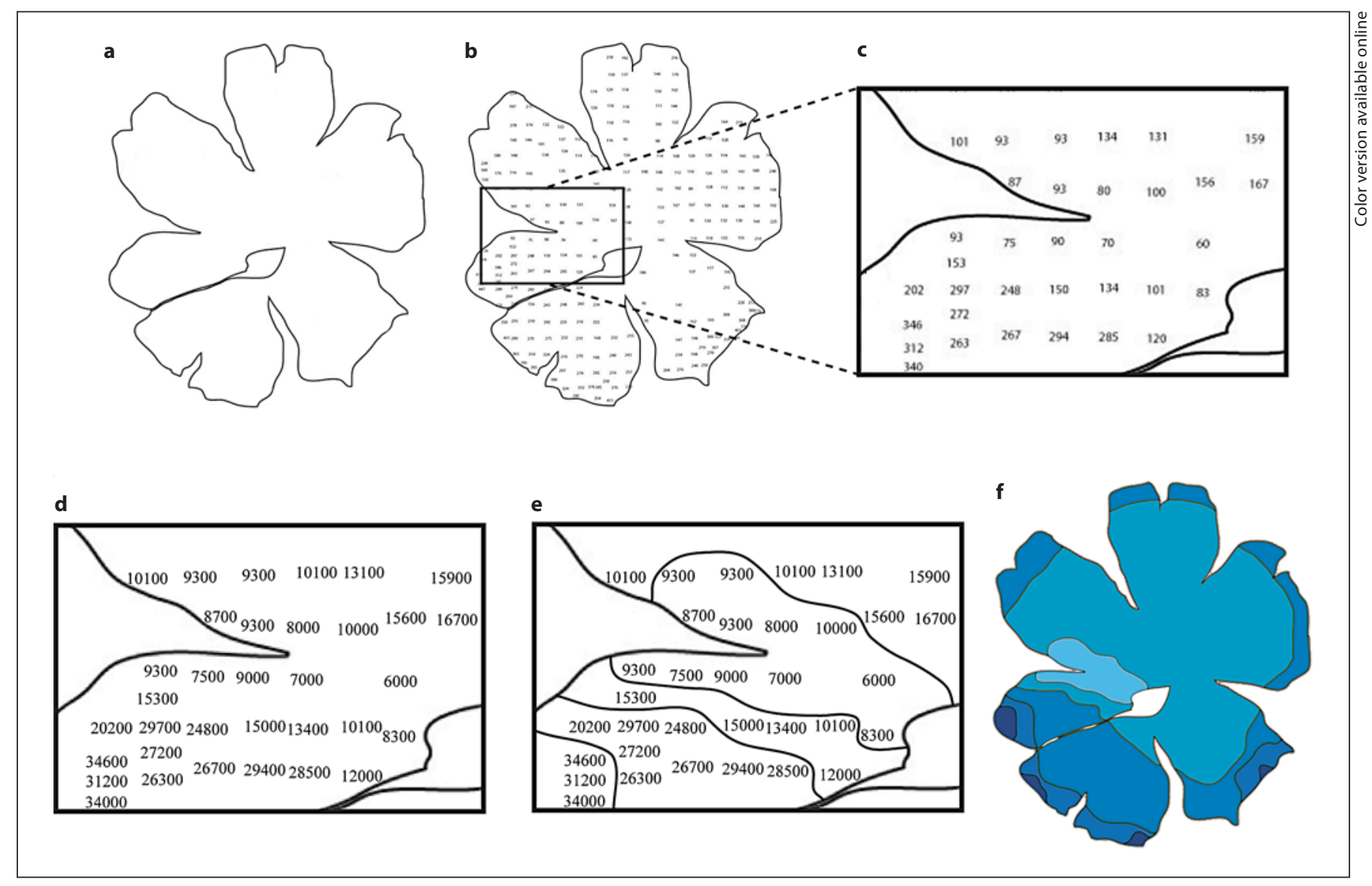

Fig. 7. Topographic map creation. a Outlined retina. Note that the optic nerve head and falciform process have been excluded from the retina. b Retina containing sample counts. c Each numeral represents the number of cells counted within a counting frame of $100 \mu \mathrm{m}^{2}$. d The counts are converted to square millimetres. In this example, each numeral is multiplied by $10^{2}$; thus, a measurement of 93 cells $/ 100 \mu \mathrm{m}^{2}$ would be 9,300 cells $/ \mathrm{mm}^{2}$. e Iso-density lines can then be constructed by interpolation between cell distribution counts. f Completed topographic map, with progressively darker blue indicating increasing cell distributions. the boundaries of the $10 \times 10$ graticule. To prevent double counting, only count cells that lie solely within each square grid and 'touch' only two sides (e.g. top and right sides of the square grid). Perform a few practice counts to ensure accuracy and reproducibility. Counters available include mechanical counter wheels and electronic types. For calibration, note the area of the graticule field size for each objective used for counting and determine the size of the sampling area in square millimetres. Accuracy will be improved if cell counts per graticule range between 20 and 200 cells. Consider the potential range of cell densities in the retina when selecting objective strength. It may be necessary to examine regions of the retina to estimate cell density before commencing counting.

Count the number of cells in each sampling location and then move the microscope stage to the next sampling location and continue counting. Subsample the entire retina in a methodical pattern. Note that in areas of rapid changes in cell density, the level of subsampling may have to be increased, i.e. in high-density areas associated with areae centrales and streaks, in order to accurately define and account for rapid topographical changes in density (fig. 7b). Occasionally, it may not be possible to count the cells in the current sampling area due to the cells being oriented on their side, damage to the retina, inadequate removal of the vitreous or the staining not being properly timed (or appropriately adjusted for retinal thickness/size). If this occurs, move on to the next sampling area and try and determine the source of error, so it can be corrected for the next retina. In addition, accurate counting may not be possible when the number of sublaminae (e.g. in the ganglion cell layer) do not allow one 
to differentiate the number of cells over multiple layers even with fine adjustment of the fine focus of the microscope.

\section{Mapping Using Stereological Computer Software}

Use a compound microscope fitted with an $\mathrm{X}, \mathrm{Y}$ and $\mathrm{Z}$ motorized stage and linked to a computer running stereological software such as Stereo Investigator (MicroBrightField) to digitize the retina under low power. On the computer, outline the limits of the retinal borders along the radial cuts and any internal structures such as a pecten or falciform process.

Using the stereological software, place random and systematic counting boxes on a grid that covers the entire retina. About 200 counting points should be placed on a retina. The size of the counting box and intervals between counting points will be determined by the size of the retina. For example, for a retina that can be covered by a 750 $\times 750-\mu \mathrm{m}$ grid, use a $25 \times 25-\mu \mathrm{m}$ counting box. However, this may vary depending on cell densities, as counts in any given box should be between 20 and 200 cells. Too few counts reduce the accuracy, while too many counts require an excessive amount of time.

After sampling the entire retina, locate areas of higher cell density such as an area centralis, fovea or horizontal/ visual streak and perform higher-frequency sampling.

To determine if enough counts are being performed, calculate the Schaffer CE, which indicates the precision of the cell number estimates [Fileta et al., 2008]. An acceptable $\mathrm{CE}$ can be calculated using the following equation:

$\mathrm{CE}=1 / \sqrt{\mathrm{Q}}$

where $\mathrm{Q}$ is the number of cells counted within a counting frame and the CE should be less than 0.10 .

\section{Creation of a Topographic Map}

Convert sample counts per graticule area to counts per square millimetre (fig. 7d). Examine the calibrated cell counts and look for patterns in the cell distribution. Draw iso-density lines or contours that connect areas with similar cell densities. If an iso-density line indicates a value between two counts, draw the line to fall between the two points. The accurate position of this point can be located by extrapolation using the lines on the graph paper. The separation of the iso-density contours is arbitrary but must reflect changes in density across the whole retina (fig. 7e).

Locate areas with higher cell densities such as an area centralis, fovea or horizontal/visual streak. Recount areas of high cell density with a smaller distance between sampling areas to determine the rate of change in density.
Find the peak cell density (in all specializations if more than one) to be used in subsequent calculations of peak spatial resolving power. Higher cell counts may be found along radial cuts. The combination of the downward pressure that occurs as a result of the radial cuts and the reduced thickness of the peripheral retina where shrinkage may be greater results in cell densities being artificially elevated. Therefore, make sure to use a new scalpel blade or very sharp scissors for making peripheral slits and avoid counting along radial cuts.

Draw all iso-density contours as smoothed lines either by hand or preferably using a graphics program such as Adobe Illustrator (Adobe Systems Inc., USA) or the open source software Inkscape. The final topography map should also contain the retinal outline, the position of natural landmarks (e.g. optic nerve head, falciform process, pecten, conus), the retinal orientation and a scale bar (fig. 7f).

Calculation of Spatial Resolving Power

For teleosts, use Matthiessens's ratio [Matthiessen, 1886]. The distance from the centre of a lens to the retina (PND) is 2.55 times the radius ( $r$ ) of the lens, as follows:

$\mathrm{PND}=2.55{ }^{*} \mathrm{r}$

For birds, the PND is approximately 0.60 times the axial length (L) of the eye [Hughes, 1977; Martin, 1993]:

$\mathrm{PND}=0.60 * \mathrm{~L}$

The angle $(\alpha)$ subtending $1 \mathrm{~mm}$ on the retina is equal to

$\tan \alpha=1 \mathrm{~mm} / \mathrm{PND}$

Spatial resolution is then calculated by obtaining the number of cells subtended by 1 degree of visual arc: PND

cells per degree = density at area of peak cell distribution/

At least 2 cells are needed to distinguish the dark and light boundaries that make up 1 cycle of grating of the highest resolvable frequency:

cycles per degree $=$ cells per degree $/ 2$

For more detailed information on calculating spatial resolving power, see the studies of Collin and Pettigrew [1989] and Pettigrew et al. [1988].

\section{Sample Experiment}

The retinal wholemount technique is an invaluable method to visualize the retina of an animal. By examin- 

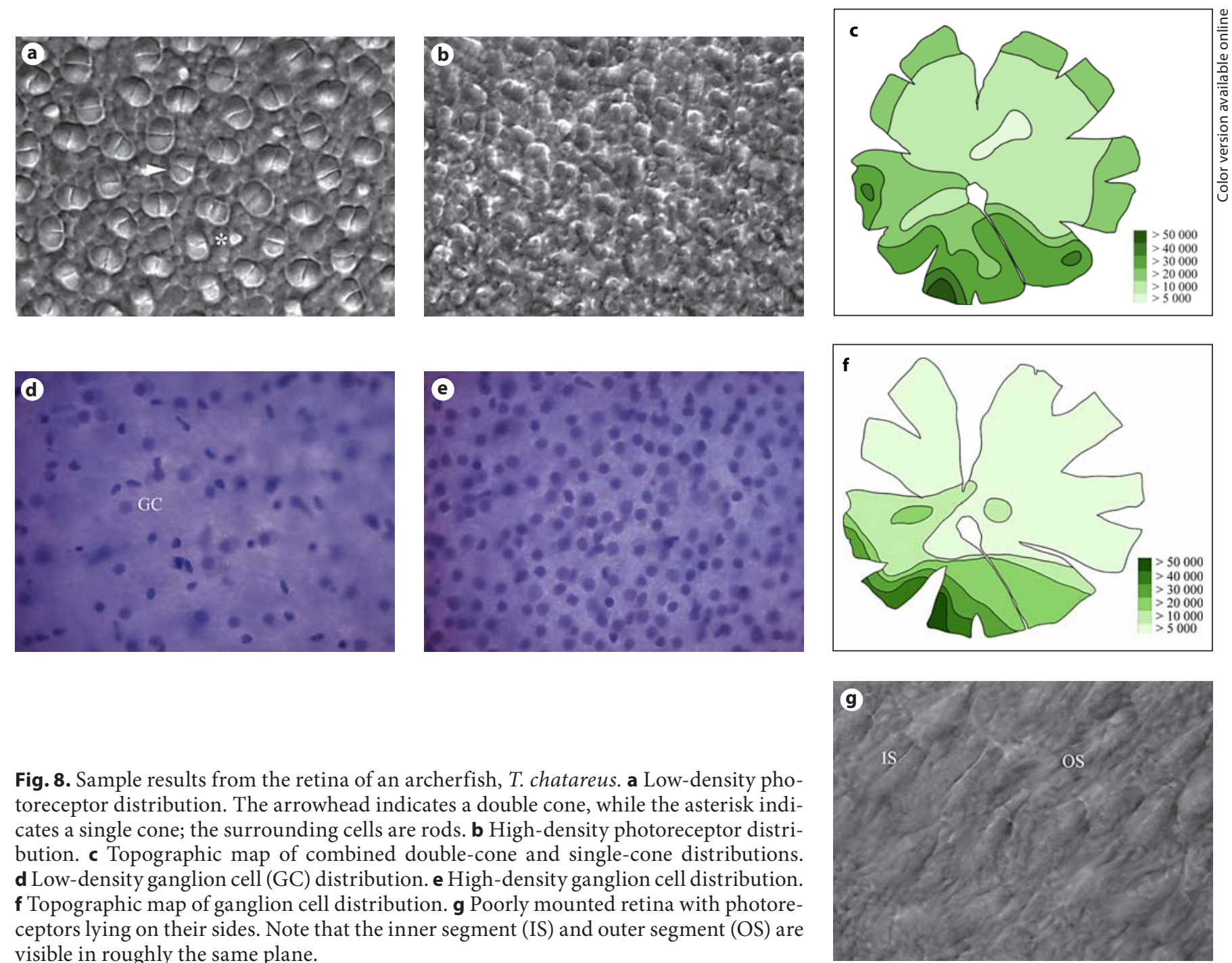

Fig. 8. Sample results from the retina of an archerfish, T. chatareus. a Low-density photoreceptor distribution. The arrowhead indicates a double cone, while the asterisk indicates a single cone; the surrounding cells are rods. b High-density photoreceptor distribution. c Topographic map of combined double-cone and single-cone distributions. d Low-density ganglion cell (GC) distribution. e High-density ganglion cell distribution. f Topographic map of ganglion cell distribution. g Poorly mounted retina with photoreceptors lying on their sides. Note that the inner segment (IS) and outer segment (OS) are visible in roughly the same plane.

ing the retina in toto, numerous features, including the topographic arrangement and density of neurons, the peak spectral sensitivities of photoreceptors and the location, size and shape of fundal landmarks, can be ascertained. These data can then be used to elucidate the neuroethology of the animal as demonstrated by the following archerfish example.

The rather unusual foraging behaviour of the archerfish (T. chatareus) is mirrored in its retinal topography. $T$. chatareus captures its prey by spitting out a stream of water to knock insects into the water, where they can be captured. The different refractive indices of water and air make this prey capture technique optically challenging, as the archerfish must compensate for the bending of light during both the prey attack and prey recovery phas- es [Temple, 2007]. We analysed the retinal topography of the archerfish by closely following the retinal wholemount technique and found 3 retinal specializations that project upwards and forwards for viewing targets both above and below the water. Briefly, archerfish were darkadapted for $2 \mathrm{~h}$, then the eyes were removed and fixed, and finally the retina was extracted. Due to the presence of areas of high cell density where the RPE was difficult to remove, the retinas were bleached as described above.

We wholemounted retinas for photoreceptor visualization and measurements of changes in density. Three retinal specializations were identified, 2 of low (fig. 8a) and 1 of high (fig. 8b) relative density. Next, we developed topographic maps of cone photoreceptor distributions and determined that the ventral retina had higher photoreceptor 
densities (greater than 22,500 cells $/ \mathrm{mm}^{2}$; fig. $8 \mathrm{c}$ ). The ventral area, which is aligned with the projection of Snell's window, contains 3 smaller areas of even higher cell densities (each greater than 40,000 cells $/ \mathrm{mm}^{2}$ ). Temporal and nasal acute zones that allow the archerfish to look out for predators or prey in the rostral and caudal regions of their visual field, respectively, were discovered in addition to a ventral area (greater than 50,000 cells $/ \mathrm{mm}^{2}$ ) that aligns with the spitting angle and is used to view aerial targets. By flipping and then staining the retina, we were able to visualize the ganglion cell distribution (fig. $8 \mathrm{~d}, \mathrm{e}$ ) in the same eye. We found the ganglion cell distribution to be similar to that of the photoreceptors, with the highest densities occurring in the ventral region of the retina (fig. 8f). At this location, convergence ratios between cones and ganglion cells were found to be nearly $1: 1$, confirming the functional significance of this region in subserving high visual acuity in the behaviour of the archerfish, which preys on small insects above the water and 'shoots' them down with a small stream of water.

\section{Discussion}

The accessibility of the vertebrate retina was first recognized over 120 years ago [Chievitz, 1889; Dogiel, 1891; Dogiel, 1895], when the retina was preserved and extracted from the eyecup in its entirety and used primarily for topographic analysis of neurons. By carefully freeing the retina from the underlying RPE and choroidal tissue, the retinal tissue could be 'wholemounted' flat onto a glass slide to visualize cell somata and their spatial organization. In the early years, the technique was particularly useful for staining individual neurons using the Golgi technique [Golgi, 1885] or silver impregnation [Rushton, 1959] but was later modified, whereby, after an infusion of methylene blue, entire populations of retinal cells could be visualized. This allowed for some of the first examinations of retinal cell topography.

Selective pressures on visual function are reflected in the diversity of specializations in the retina, which are areas devoted to high-acuity vision. The spacing of retinal neurons is smallest within these retinal specializations, yielding high sampling of an image (i.e. high-cell density areas with high visual resolution). There are different types of retinal specializations (e.g. areae, fovea, streaks) that have been identified in almost all vertebrates examined. An area centralis is a concentric increase in ganglion cell density towards the centre of the retina and is present in many species of mammals [Kolb and Wang,
1985; Murayama et al., 1995; Schmid et al., 1992]. A fovea is characterized by a displacement of the inner layers of the retina and is associated with an increased packing of photoreceptors with elongated and smaller-diameter outer segments beneath the foveal pit, as well as high densities of ganglion cells in the perifoveal region. A fovea can be convexiclivate, with steep sloping sides (found in some fishes and birds), or concaviclivate, with a shallow depression (found in monkeys and humans). Some predatory birds possess two foveae, namely a temporal fovea, which subtends the binocular visual space, and a monocular fovea, which projects close to the laterally pointing optical axis [Moroney and Pettigrew, 1987]. A horizontal streak is an area of high ganglion cell density located across the central region of the retina and is common in species that occupy habitats where the visual field is predominated by a horizon (the air-land or air-water interface for terrestrial species or the water-substrate interface for aquatic species), such as some coral reef fish, ostriches and hyenas, among others.

When one dissects an eye from a previously unstudied organism, there are a number of gross morphological differences to be taken into account. These include the following: (1) the position and shape of the optic nerve head, including multiple [Dunn-Meynell and Sharma, 1987, 1988] and elongated [Collin et al., 2000] optic nerve heads; (2) any remaining scars due to the healing (or partial healing) of the embryonic fissure or falciform process [Collin and Pettigrew, 1988a]; (3) the shape and depth of any foveal pit or depression in the retina [Collin and Collin, 1999; Collin et al., 2000; Moroney and Pettigrew, 1987; Wood, 1917]; (4) retinal thickening(s) across the retinal meridian typically indicating the position of one or more horizontal/visual streaks [Munk, 1970]); (5) differences in the size, shape and attachment of the lens [Gustafsson et al., 2010; Khorramshahi et al., 2008]; (6) the presence or absence of vitreal vascularization, a conus or a pecten [Collin, 1989a; Hanyu, 1962; Nguyen, 1970; Smith et al., 1996; Yu et al., 2009], and (7) colored eye shine produced by any tapetal material underlying the retina to increase visual sensitivity [Braekevelt, 1986, 1990; Collin and Collin, 1993; Nicol, 1981]. The presence of these morphological and, in many cases, species- or taxon-specific variables presents technical difficulties. We hope this review alleviates many of these issues by our modifications to Stone's [1981] techniques in terms of fixation, perfusion, removal of the vitreous humour and staining of the retinal cells with cresyl violet.

The viscosity of the vitreous humour appears to be particularly different across taxa, which may be due to the 
relative effects of fixation and/or the role of the vitreous in providing additional support for the lens and/or the intraocular pressure. These differences need to be considered when extracting the retinal tissue. Therefore, we have provided instructions to either remove the vitreous body in toto, as is possible in rabbits, in small pieces or via enzymatic digestion, as required in some deep-sea teleosts.

The method of removal of the RPE can also differ between species and within individual retinas. In species in which the RPE retracts away from the photoreceptor array (sclerad) in the dark (retinomotor movement) to enhance sensitivity (found in some teleosts, amphibians and, to a lesser extent, reptiles), its removal can be straightforward after dark adaptation. In cartilaginous fishes or elasmobranchs, the RPE is actually incorporated within a choroidal tapetum and therefore can be easily dissected away from the retina. In the archerfish, the RPE is easily removed except in the ventro-temporal retina, which has a high neuronal density. In avian and mammalian eyes with similarly located acute zones, where the $\mathrm{RPE}$ is extremely difficult to remove, we recommend bleaching the retina to render the RPE ineffective in absorbing transmitted light, thereby aiding the analysis of cell density changes in the wholemounted retina.

An additional issue to be considered is the inclusion of non-ganglion cell populations (not possessing an axon projecting to the visual centers of the brain), such as amacrine and glial cells, located within the ganglion cell layer in the measurement of cell density, which could result in an overestimate of spatial resolving power [Hart, 2002; Theiss et al., 2007]. This effect will be more or less pronounced depending on the method used to estimate spatial resolving power. If the sampling theorem is used [Hughes, 1977], only up to about 33\% of the variability in resolving power will be influenced by ganglion cell density estimates, as most of the variability is explained by eye size [Dolan and Fernández-Juricic, 2010]. However, if retinal ganglion cell density is estimated from the retinal specialization, the potential bias is greatly reduced because of the lower density of amacrine cells in that portion of the retina [Hayes and Holden, 1983]. Additionally, the inclusion of the non-ganglion cell population does not appear to alter retinal topography [Collin and Pettigrew, 1988b], although it may vary among species, warranting careful examination of each species if precise values are required. More accurate measures of spatial resolving power can be obtained by retrogradely labelling the retinal ganglion cells from the optic nerve and/or the retinotopic centers within the brain [Bailes et al., 2006; Pettigrew et al., 1988]. However, retrograde labelling is less effective when areas of specialization are located more peripherally. For example, using retrograde labelling, ganglion cell densities in the archerfish were estimated to be approximately 5,000 cells $/ \mathrm{mm}^{2}$ [Segev et al., 2007], while using the retinal wholemount technique, we obtained values of over 50,000 cells $/ \mathrm{mm}^{2}$ (fig. 8 f).

A potential disadvantage of using the wholemount technique is the inability to precisely assess which part of the visual field is subtended by a specific part of the retina once it has been flattened. The reason behind this problem is that during the wholemounting process, a number of radial slits are placed in the retina to flatten it. As a result, the retina assumes an artificial and somewhat distorted shape, which is no longer a valid representation of its natural visual field [Chelvanayagam, 2000]. A more accurate method of representing the extent, overlap and projected position of regions of acute vision within the visual field of any species is to employ a stereotaxic approach using a reversible visual ophthalmoscope to map the visual field in combination with the wholemount technique [Collin and Northcutt, 1995]. Another alternative is to use an ophthalmoscopic reflex to map out the visual space encompassed by the projection of retinal margins and some key retinal landmarks (e.g. pecten) [Martin, 1984]. The retinal topographic map could be combined with this ophthalmoscopic reflex to determine the projection of the retinal specialization [Fernández-Juricic et al., 2011]. This technique has been successfully used to study the configurations of the visual field across different bird species [Fernández-Juricic et al., 2008; O’Rourke et al., 2010] but has not yet been used in aquatic eyes.

The retinal wholemount technique may not be a feasible procedure when a species' eyes are too small for dissection or when the size of neurons (photoreceptor cells) is beyond the optical limits of the light microscope. In these rare cases, the only way to obtain these data is by the reconstruction of sectioned material. Such a reconstruction can be performed using paraffin sections, cryosections or serial resin sections, although this is timeconsuming and requires special methods (optical dissector method) [Coggeshall and Lekan, 1996; Tandrup, 1993] and is complicated by the difficulty in maintaining reference points due to retinal thickening and shrinkage. Nevertheless, some studies have created two-dimensional topographic maps of the retina from serial sections obtained using histological methods [Wilhelm and Straznicky, 1992]. Sectioning is particularly useful for those studies concentrating on species with banked rows of photoreceptors and accessory globes, e.g. some species of deep-sea teleosts, such as the smooth head Bajacalifor- 
nia sp. that possesses 28 banks of rods underlying a deep convexiclivate fovea [Locket, 1985]. This approach yields low-resolution topographic information but high-resolution information regarding the arrangement, packing and density of neurons.

By making available the details of an enhanced wholemount technique based on a wider range of species, we hope to continue to promote the use of this technique. The wholemount technique is a powerful tool in comparative neurobiology and visual ecology. New topographic maps can be submitted to the Retinal Topography Database (http://www.retinalmaps.com.au/) for future comparative analyses on the evolution of the vertebrate visual system.

\section{Acknowledgments}

We would like to thank Tom Gallagher, Jeff Lucas, Megan Gall, Lauren Brierley, Patrice Baumhardt, Jacquelyn Randolet and Nathan Robinson for providing useful comments on an earlier version of the draft. We would also like to thank João Paulo Coimbra for his useful discussion and instructions for stereology. E.F.-J. and B.A.M. were partially supported by the National Science Foundation (IOS-0641550/0937187 to E.F.-J.). S.P.C. would like to thank the Australian Research Council and the Western Australia State Government for their continued support. S.E.T. was supported by postdoctoral fellowships from The University of Queensland and the Natural Sciences and Engineering Research Council of Canada. J.F.P.U. was supported by an Endeavour International Postgraduate Research Scholarship and a University of Queensland International Living Allowance Scholarship.

\section{References}

Bailes HJ, Trezise AEO, Collin SP (2006): The number, morphology, and distribution of retinal ganglion cells and optic axons in the Australian lungfish Neoceratodus forsteri (Krefft 1870). Vis Neurosci 23:257-273.

Bowmaker JK, Heath LA, Wilkie SE, Hunt DM (1997): Visual pigments and oil droplets from six classes of photoreceptor in the retinas of birds. Vision Res 37:2183-2194.

Brach V (1977): The functional significance of the avian pecten: a review. The Condor 79: 321-327.

Braekevelt CR (1986): Fine structure of the tapetum cellulosum of the grey seal (Halichoerus grypus). Acta Anat (Basel) 127:81-87.

Braekevelt CR (1990): Fine structure of the feline tapetum lucidum. Anat Histol Embryol 19: 97-105.

Chelvanayagam DK (2000): Interpreting the distortion associated with a retinal whole mount. J Theor Biol 205:443-455.

Chievitz JH (1889): Untersuchungen über die Area centralis retinae. Arch Anat Physiol 139-196.

Coggeshall RE, Lekan HA (1996): Methods for determining numbers of cells and synapses: a case for more uniform standards of review. J Comp Neurol 364:6-15.

Collin SP (1989a): Topographic organization of the ganglion cell layer and intraocular vascularization in the retinae of two reef teleosts. Vision Res 29:765-775.

Collin SP (1989b): Topography and morphology of retinal ganglion cells in the coral trout Plectropoma leopardus (Serranidae): a retrograde cobaltous-lysine study. J Comp Neurol 281:143-158.

Collin SP, Collin HB (1993): The visual system of the Florida garfish, Lepisosteus platyrhincus (Ginglymodi). I. Retina. Brain Behav Evol 42:77-97.

Collin SP, Collin HB (1999): The foveal photoreceptor mosaic in the pipefish, Corythoichthyes paxtoni (Syngnathidae, Teleostei). Histol Histopathol 14:369-382.
Collin SP, Davies WL, Hart NS, Hunt DM (2009): The evolution of early vertebrate photoreceptors. Philos Trans R Soc Lond B Biol Sci 364:2925-2940.

Collin SP, Hart NS, Wallace KM, Shand J, Potter IC (2004): Vision in the southern hemisphere lamprey Mordacia mordax: spatial distribution, spectral absorption characteristics, and optical sensitivity of a single class of retinal photoreceptor. Vis Neurosci 21:765-773.

Collin SP, Lloyd DJ, Wagner H-J (2000): Foveate vision in deep-sea teleosts: a comparison of primary visual and olfactory inputs. Philos Trans R Soc Lond B Biol Sci 355:1315-1320.

Collin SP, Northcutt RG (1995): The visual system of the Florida garfish, Lepisosteus platyrhincus (Ginglymodi). IV. Bilateral projections and the binocular visual field. Brain Behav Evol 45:34-43.

Collin SP, Pettigrew JD (1988a): Retinal topography in reef teleosts. II. Some species with prominent horizontal streaks and high-density areae. Brain Behav Evol 31:283-295.

Collin SP, Pettigrew JD (1988b): Retinal ganglion cell topography in teleosts: a comparison between Nissl-stained material and retrograde labelling from the optic nerve. J Comp Neurol 276:412-422.

Collin SP, Pettigrew JD (1989): Quantitative comparison of the limits on visual spatial resolution set by the ganglion cell layer in twelve species of reef teleosts. Brain Behav Evol 34:184-192.

Collin SP, Trezise AEO (2004): The origins of colour vision in vertebrates. Clin Exp Optom 87:217-223.

Collin SP, Trezise AE (2006): Evolution of colour discrimination and its implications for visual communication; in Ladich F, Collin SP, Moller P, Kapoor BG (eds): Communication in Fishes. Enfield, Science Publishers, pp 303-335.

Dacey DM, Peterson MR (1992): Dendritic field size and morphology of midget and parasol ganglion cells of the human retina. Proc Natl Acad Sci USA 89:9666-9670.
Dieterich CE, Dieterich HJ, Hildebrand R (1976): Comparative electron microscopic studies on the conus papillaris and its relationship to the retina in night and day active geckos. Graefes Arch Clin Exp Ophthalmol 200:279-292.

Dogiel AG (1891): Ueber die nervösen Elemente in der Retina des Menschen. Arch Mikr Anat 38:317-344.

Dogiel AG (1895): Die Retina der Vogel. Arch Mikr Anat 44:622-648.

Dolan T, Fernández-Juricic E (2010): Retinal ganglion cell topography of five species of ground-foraging birds. Brain Behav Evol 75: 111-121.

Dunlop S, Moore S, Beazley L (1997): Changing patterns of vasculature in the developing amphibian retina. J Exp Biol 200:2479-2492.

Dunn-Meynell AA, Sharma SC (1987): Visual system of the channel catfish (Ictalurus punctatus). II. The morphology associated with the multiple optic papillae and retinal ganglion cell distribution. J Comp Neurol 257:166-175

Dunn-Meynell AA, Sharma SC (1988): Visual system of the channel catfish (Ictalurus punctatus). III. Fiber order in the optic nerve and optic tract. J Comp Neurol 268:299-312.

Ehrlich D (1981): Regional specialization of the chick retina as revealed by the size and density of neurons in the ganglion cell layer. J Comp Neurol 195:643-657.

Fernández-Juricic E, Gall MD, Dolan T, O'Rourke C, Thomas S, Lynch JR (2011): Visual systems and vigilance behaviour of two ground-foraging avian prey species: whitecrowned sparrows and California towhees. Anim Behav 81:705-713.

Fernández-Juricic E, Gall MD, Dolan T, Tisdale V, Martin GR (2008): The visual fields of two ground-foraging birds, House Finches and House Sparrows, allow for simultaneous foraging and anti-predator vigilance. Ibis 150: 779-787. 
Fileta JB, Huang W, Kwon GP, Filippopoulos T, Ben Y, Dobberfuhl A, Grosskreutz CL (2008): Efficient estimation of retinal ganglion cell number: a stereological approach. J Neurosci Methods 170:1-8.

-Frank BL, Goldberg S (1983): Multiple optic fiber patterns in the catfish retina. Invest Ophthalmol Vis Sci 24:1429-1432.

- Garamszegi LZ, Moller AP, Erritzoe J (2002): Coevolving avian eye size and brain size in relation to prey capture and nocturnality. Proc Biol Sci 269:961-967.

Golgi C (1885): Sulla fina anatomia degli organi centrali del sistema nervoso. Reggio Emilia, Stefano Calderini e Figlio.

-Gustafsson OS, Ekström P, Kröger RH (2010): A fibrous membrane suspends the multifocal lens in the eyes of lampreys and African lungfishes. J Morphol 271:980-989.

Hanyu I (1962): Intraocular vascularization in some fishes. Can J Zool 40:87-106.

Hart NS (2001): Variations in cone photoreceptor abundance and the visual ecology of birds. J Comp Physiol A 187:685-697.

Hart NS (2002): Vision in the peafowl (Aves: Pavo cristatus). J Exp Biol 205:3925-3935.

-Hart NS, Partridge JC, Cuthill IC (1999): Visual pigments, cone oil droplets, ocular media and predicted spectral sensitivity in the domestic turkey (Meleagris gallopavo). Vision Res 39:3321-3328.

Hayes BP, Holden AL (1983): The distribution of displaced ganglion-cells in the retina of the pigeon. Exp Brain Res 49:181-188.

Hughes A (1977): The topography of vision in mammals of contrasting life style: comparative optics and retinal organisation; in Crescitelli F (ed): The Visual System of Vertebrates. Berlin, Springer, vol 2, pp 613-756.

Khorramshahi O, Schartau JM, Kröger RHH (2008): A complex system of ligaments and a muscle keep the crystalline lens in place in the eyes of bony fishes (teleosts). Vision Res 48:1503-1508.

Koch PC, Seebacher C, Hess M (2010): 3D-topography of cell nuclei in a vertebrate retina - a confocal and two-photon microscopic study. J Neurosci Methods 188:127-140.

Kolb H, Wang HH (1985): The distribution of photoreceptors, dopaminergic amacrine cells and ganglion cells in the retina of the North American opossum (Didelphis virginiana). Vision Res 25:1207-1221.

Levine JS, Macnichol EF, Collins BA, Kraft T (1979): Intraretinal distribution of cone pigments in certain teleost fishes. Science 204: 523-526.

Lichstein HC, Soule MH (1944): Studies of the effect of sodium azide on microbic growth and respiration. J Bacteriol 47:221-230.

Litherland L, Collin SP (2008): Comparative visual function in elasmobranchs: spatial arrangement and ecological correlates of photoreceptor and ganglion cell distributions. Vis Neurosci 25:549-561.

Locket NA (1985): The multiple bank rod fovea of Bajacalifornia drakei, an Alepocephalid deep-sea teleost. Proc R Soc Lond B Biol Sci 224:7-22.
Martin GR (1984): The visual fields of the tawny owl, Strix aluco L. Vision Res 24:1739-1741.

Martin GR (1993): Producing the image; in Zeigler HP (ed): Vision, Brain and Behaviour in Birds. Cambridge, MIT Press, pp 5-24.

Matthiessen L (1886): Ueber den physikalischoptischen Bau des Auges der Cetaceen und der Fische. Pflügers Arch Ges Physiol 38: 521-528.

Moroney MK, Pettigrew JD (1987): Some observations on the visual optics of kingfishers (Aves, Coraciformes, Alcedinidae). J Comp Physiol A 160:137-149.

Munk O (1970): On the occurrence and significance of horizontal band-shaped retinal areas in teleosts. Vidensk Meddr Dansk Naturh Foren 133:85-120.

-Murayama T, Somiya H, Aoki I, Ishii T (1995): Retinal ganglion-cell size and distribution predict visual capabilities of Dall's porpoise. Mar Mammal Sci 11:136-149.

- Nguyen J (1970): The conus papillaris of reptiles. I. Ultrastructure in oplurus Oplurus cyalurus (Iguanidae). Z Mikr Anat Forsch 82:17-28.

Nicol JAC (1981): Tapeta lucida of vertebrates; in Eroch JH, Tobey FL Jr (eds): Vertebrate Photoreceptor Optics. New York, Springer, pp 401-431.

- Ollivier FJ, Samuelson DA, Brooks DE, Lewis PA, Kallberg ME, Komaromy AM (2004): Comparative mophology of the tapetum lucidum (among selected species). Vet Ophthamol 7:11-22.

O'Rourke CT, Hall MI, Pitlik T, Fernández-Juricic E (2010): Hawk eyes. I. Diurnal raptors differ in visual fields and degree of eye movement. PLoS One 5:e12802.

Pettigrew JD, Dreher B, Hopkins CS, McCall MJ, Brown M (1988): Peak density and distribution of ganglion cells in the retinae of microchiropteran bats: implications for visual acuity. Brain Behav Evol 32:39-56.

Rushton WAH (1959): Giant ganglion cells in the cat's retina. J Physiol 111:26-27P.

Schiviz AN, RufT, Kuebber-Heiss A, Schubert C, Ahnelt PK (2008): Retinal cone topography of artiodactyl mammals: influence of body height and habitat. J Comp Neurol 507:13361350.

Schmid KL, Schmid LM, Wildsoet CF, Pettigrew JD (1992): Retinal topography in the koala (Phascolarctos cinereus). Brain Behav Evol 39:8-16.

- Segev R, Schneidman E, Goodhouse J, Berry MJ (2007): Role of eye movements in the retinal code for a size discrimination task. J Neurophysiol 98:1380-1391.

-Smith BJ, Smith SA, Braekevelt CR (1996): Fine structure of the pecten oculi of the barred owl (Strix varia). Histol Histopathol 11:89-96.

Somiya H (1980): Fishes with eye shine: functional morphology of guanine type tapetum lucidum. Mar Ecol Prog Ser 2:9-26.

Stone J (1981): The Wholemount Handbook. A Guide to the Preparation and Analysis of Retinal Wholemounts. Sydney, Maitland Publications.
Takechi M, Kawamura S (2005): Temporal and spatial changes in the expression pattern of multiple red and green subtype opsin genes during zebrafish development. J Exp Biol 208:1337-1345

Takei S, Somiya H (2002): Guanine-type retinal tapetum and ganglion cell topography in the retina of a carangid fish, Kaiwarinus equula. Proc Biol Sci 269:75-82.

Tandrup T (1993): A method for unbiased and efficient estimation of number and mean volume of specified neuron subtypes in rat dorsal-root ganglion. J Comp Neurol 329: 269-276.

Temple SE (2007): Effect of salinity on the refractive index of water: considerations for archer fish aerial vision. J Fish Biol 70:1626-1629.

-Temple SE (2011): Why different regions of the retina have different spectral sensitivities: a review of mechanisms and functional significance of intraretinal variability in spectral sensitivity in vertebrates. Vis Neurosci 28 : 281-293.

Temple S, Hart NS, Marshall NJ, Collin SP (2010): A spitting image: specializations in archerfish eyes for vision at the interface between air and water. Proc Biol Sci 277:26072615.

Thanos S, Pavlidis C, Mey J, Thiel HJ (1992): Specific transcellular staining of microglia in the adult rat after traumatic degeneration of carbocyanine-filled retinal ganglion cells. Exp Eye Res 55:101-117.

Theiss S, Lisney T, Collin S, Hart N (2007): Colour vision and visual ecology of the bluespotted maskray, Dasyatis kuhlii Müller \& Henle, 1814. J Comp Physiol A Neuroethol Sens Neural Behav Physiol 193:67-79.

Vaney DI, Collin SP, Young HM (1989): Dendritic relationships between cholinergic amacrine cells and direction-selective retinal ganglion cells; in Weiler R, Osbourne NN (eds): The Neurobiology of the Inner Retina. NATO ASI Series/Cell Biology. Berlin, Springer, pp 157-168.

-Vidal-Sanz M, Villegas-Pérez MP, Bray GM, Aguayo AJ (1988): Persistent retrograde labeling of adult rat retinal ganglion cells with the carbocyanine dye DiI. Exp Neurol 102: 92-101.

Wilhelm M, Straznicky C (1992): The topographic organization of the retinal ganglion cell layer of the lizard Ctenophorus nuchalis. Arch Histol Cytol 55:251-259.

-Wong KW, Adolph AR, Dowling JE (2005): Retinal bipolar cell input mechanisms in giant danio. I. Electroretinographic analysis. J Neurophysiol 93:84-93.

Wong ROL, Meister M, Shatz CJ (1993): Transient period of correlated bursting activity during development of the mammalian retina. Neuron 11:923-938.

Wood CA (1917): The Fundus Oculi of Birds, Especially as Viewed by the Ophthalmoscope. A Study in Comparative Anatomy and Physiology. Chicago, Lakeside Press.

-Yu CQ, Schwab IR, Dubielzig RR (2009): Feeding the vertebrate retina from the Cambrian to the Tertiary. J Zool 278:259-269. 